\title{
Positive relationships between golf performance variables and upper body power capabilities
}

Graeme G. Sorbie Jonathan Glen

Ashley K. Richardson

This is a non-final version of an article published in final form in:

Sorbie, G.G.; Glen, J.; Richardson, A.K. (2020) 'Positive relationships between golf performance variables and upper body power capabilities'. Journal of Strength and Conditioning Research.

DOI: $10.1519 / J S C .0000000000003788$ 
1 Journal of Strength \& Conditioning Research

2 Positive Relationships between Golf Performance Variables and Upper Body Power 3 Capabilities.

4 Running head: Correlation between upper body power and golf performance variables

5

6 Location of study: Abertay University Research Laboratory and Drumoig Driving Range

7

$8 \quad$ Graeme G. Sorbie $^{1}$, Jonathan. Glen ${ }^{1}$ and, Ashley K. Richardson ${ }^{1}$

9 1School of Applied Sciences, Sport and Exercise Science Division, Abertay University, 10 United Kingdom.

Address correspondence to Dr. Graeme Sorbie, School of Applied Sciences, Sport and Exercise Science Division, Abertay University, United Kingdom; Dundee, DD1 1HG,

Email: g.sorbie@abertay.ac.uk, Tel No: +44 (0)1382 308015, ORCID ID: 0000-00023362-267X.

Disclosure statement: No potential conflict of interest was reported by the authors.

Data availability: The data for this study is available on the Abertay University pure system which has an open access feature. 


\section{ABSRACT}

The importance of lower body and trunk strength and power, as well as upper body strength in golf is well documented, however the relationship between upper body power and golf performance has yet to be determined. Therefore, the purpose of the study was to investigate the relationships between golf performance and upper body power. Thirteen golfers (mean \pm SD: age: $30 \pm 7$ years and handicap: $6.1 \pm 4.9$ ) participated in the study. Club head velocity (CHV) and ball velocity were measured during the golf test. In order to assess upper body power, subjects completed a ballistic bench press and upper body Wingate test. Pearson product-moment correlations were used to assess the relationships between golf performance and upper body power. The results demonstrated that there were strong relationships between ballistic bench press and CHV and ball velocity when using the driver $(r>0.6-0.7)$, and moderate to strong relationships ( $r>0.4-0.6)$ when using the 7-iron. Strong relationships were found between the upper body Wingate test and CHV and ball velocity $(r>0.5-0.8)$ when using the driver and 7-iron. As a results of the findings, strength and conditioning coaches may use both the ballistic bench press test and the Wingate test as a primary assessment to measure the effectiveness of upper body training interventions with the aim of improving golf performance. Although, when performing the golf swings at higher velocities (i.e. with the driver), the ballistic bench press may be a more beneficial.

Key words: Golf Swing; CHV; Ball velocity; Golfers; Correlations 
47

48

49

50

51

52

53

54

55

56

57

\section{INTRODUCTION}

Golf is a highly competitive sport at both professional and recreational level (18). Recently, there has been an increased interest within golf specific literature with regards to performance, particularly in relation to the long game $(9,30,31)$. Long game performance takes into consideration golf shots that are performed with a full swing, including driving from the teeing area. Improving driving performance through increased distance and accuracy is a key focus for most golfers (4). Driving distance is mostly influenced by club head velocity (CHV) at the moment of impact, which directly affects ball velocity and ultimately carry distance of the golf shot (12).

The golf swing is a complex movement where both the upper and lower extremities play a key role in maximizing performance (6). Through electromyography research, high levels of muscle activation ( $~ 50 \%$ of maximum contraction) have been reported from both the upper and lower extremities at various phases of the golf swing $(1,21,26,32)$. These muscles include the pectoralis major, rhomboids and trapezius from the upper extremities and biceps femoris, gluteus maximus and vastus laterlis from the lower extremities. With these muscle activation contributions in mind, it is reasonable to suggest that golfers would be unable to generate muscular torque and power without reasonable levels of muscular strength, which both have a direct effect on CHV (15).

In addition to the strength of the muscles activated throughout the golf swing, the power of the activated musculature is also an important factor that affects CHV (10). Previous research has made an attempt to measure the relationship between lower body physical attributes including power and strength, and golf performance measures including CHV (25,33). Wells et al. (33) 
reported that if Challenge Tour golfers are able to improve a countermovement jump positive impulse by one standard deviation ( $46.85 \mathrm{~N} \cdot \mathrm{s})$, it would elicit a likely increase of $6.08 \mathrm{~km} / \mathrm{h}$ in CHV. However, no relationship was observed between isometric mid-thigh pull, peak force and rate of force development and CHV. Read et al. (25) reported significant relationships between squat jump and countermovement jump power and CHV when using the driver. In addition, Keogh et al. (15) reported a positive correlation between hack squat strength and handicap level. These previous findings demonstrate that positive relationships exist between lower body performance attributes and golf performance.

In relation to the upper body and trunk, previous research has identified a relationship between strength attributes, CHV and handicap (10,15). Specifically, Gordon et al. (10) found that the strength of the chest during a pec deck motion and total body rotational power during a hip toss correlated significantly with CHV. Similarly, Read et al. (25) reported that a medicine ball seated and rotational throw measured by distance were significantly related to CHV. In addition, Keogh et al. (15) reported that total body rotational power and bench press strength were significantly correlated with handicap. Specifically, Keogh and colleagues reported that lower handicap golfers exhibited $15.2 \%$ greater total body rotational power when compared to higher handicap golfers. Additionally, the lower handicap golfers in this study exhibited $17.4 \%$ greater bench press strength when compared to higher handicap golfers; however, the relationship between power and bench press capabilities were not assessed. As the golf swing requires high power outputs from both the upper and lower body, this is an important aspect to consider (7). 
94 Within the golf scientific community, there is an understanding of the importance of lower body and trunk strength and power, as well as upper body strength. Therefore, strength and conditioning coaches should consider these aspects when aiming to improve golfers' long game performance $(10,15,33)$. The relationship between upper body power output measures and golf performance, however, has yet to be determined. Due to the understanding that increased muscular power within the lower body and trunk area enables greater mechanical work during the golf swing, which in turn increases CHV (7), it is important to ascertain whether or not this relationship translates to the upper body. This relationship is also important when considering that many upper body resistance exercises are being incorporated in conditioning programs within the scientific literature $(7,11,17)$. Consequently, the aim of the study was to investigate the relationship between CHV and ball velocity and upper body power in experienced golfers. It was hypothesized that there would be a positive relationship between $\mathrm{CHV}$ and ball velocity and upper body power.

\section{METHOD}

\section{Experimental Approach to the Problem}

Subjects attended 3 separate testing sessions across a 10-day period, with at least 48 hours between testing conditions in order to combat muscular fatigue. Testing sessions were either conducted in the laboratory or at a local driving range. During the 3 separate testing sessions subjects completed a golf test to measure $\mathrm{CHV}$ and ball velocity, and an upper body Wingate test and ballistic bench press test to measure upper body power capabilities. Subjects were familiarized with all tests and movements prior to data collection. This design allowed the researchers to measure relationships between golf performance measures and upper body power capabilities. 


\section{Subjects}

Thirteen skilled right-handed golfers volunteered to participate in this study (mean \pm SD age: $30 \pm 7$ years; height: $180.95 \pm 5.82 \mathrm{~cm}$; body mass: $82.15 \pm 12.96 \mathrm{~kg}$; BMI $25.08 \pm 3.80$ $\mathrm{kg} / \mathrm{cm}^{2}$ and handicap: $\left.6.1 \pm 4.9\right)$. At the time of the study, subjects were required to be free from injury and have at least 5 years of experience playing golf. Subjects were also required to undertake no conditioning or resistance training 48 hours prior to the testing sessions. All subjects were informed of the risks and benefits of the study prior to any data collection. In addition, all subjects completed a PAR-Q form and signed an institutionally approved written informed consent document prior to the study commencing. Ethical approval was granted by the School of Applied Sciences at Abertay University prior to subject recruitment and testing.

\section{Procedures}

Golf Drive Performance. Prior to measuring golf performance variables, all subjects performed a standardized warm up. This consisted of upper and lower body dynamic stretches, as well as practice swings and full golf shots with the driver (Appendix 1). Following the warm-up, subjects then performed 8 golf shots with the driver, with 30 seconds rest implemented between shots (28). Following a 1 minute rest, subjects then performed 8 golf shots with the 7-iron, with 30 seconds rest also implemented between shots. During all golf shots, subjects rated each shot 1 to 5 ; with 5 being the best strike. Any ratings of 1 and 2 were excluded and additional shots were performed, up to a maximum of 12 shots with each golf club (33). All golf shots were struck from a rubber tee placed on an artificial golf mat fixed to the floor in the center of the golf bay. During each golf shot, subjects were instructed to perform their standard golf swing with the aim of maximizing distance and accuracy. Subjects were instructed to aim towards a 
target area in the middle of the range $(28,33)$. All subjects used their own driver and 7 -iron for the golf shots during testing and all subjects wore appropriate golf shoes (2).

During each golf shot, $\mathrm{CHV}$ and ball velocity were recorded. These variables were recorded using the Voice Caddie Swing Launch Monitor SC 100 GPS (La Mirada, CA, USA). The Launch Monitor was required to be positioned $1 \mathrm{~m}$ directly behind the golf ball, and positioned towards the target line of the golfer as per the manufacturer's guidelines. After each golf shot, the performance variables were logged using Microsoft Excel (Excel 2016 (v16.0)).

Ballistic Bench Press. To determine upper body power, each subject performed a ballistic bench press with a load equal to $50 \%$ of their respective 1 repetition maximum (1RM). The movement was completed on a Smith Machine, restricting the movement of the barbell to a vertical, linear plane (19). 1RM was estimated from a submaximal (3RM) load using the equation of Brzycki (3). Each subject performed 5 - 10 repetitions with a light to moderate load, progressing to heavier sets of 3 repetitions, until the 3 repetition maximum was determined. Subjects were then asked to carry out two ballistic bench press attempts at $20 \%$ of their 1RM in order to familiarize themselves with the movement. After completing this process, subjects were given a 5-minute rest period before commencing the ballistic bench press tests (5). Subjects performed $21 \mathrm{RM}$ ballistic bench throws with a 2 minute rest between repetitions (19). In order to complete the ballistic bench press, the bar was lowered until it came into contact with the chest, approximately $3 \mathrm{~cm}$ superior to the xiphoid process. The bar was then held on the chest for 1 second before throwing ballistically as high as possible. In order to ensure the correct form and consistency, the subjects' head, shoulders and hips were required to remain in contact with the bench throughout the movement (19). 
167

168

169

170

171

172

173

174

175

176

177

179

180

181

182

183

184

185

186

187

188

189

During the ballistic bench press test, peak power (W), mean power (W), relative peak power $(\mathrm{W} / \mathrm{kg}$ ) and relative mean power (W/kg) were measured using a GymAware linear position transducer (LPT) (GymAware Lite v2.10, Kinetic Performance Technology, Australia). The LPT transducer was connected to an iPhone 3 (Apple Inc., USA) via a Bluetooth connection. Prior to data measurements, the LPT was calibrated and zeroed whilst the tether was fully retracted. Following the calibration, the LPT was positioned vertically below the barbell and was attached to a magnetic weight plate, with the tether connected to the right side of the barbell. Following each trial, data were logged using Microsoft Excel.

Upper Body Cycle: In addition to the ballistic bench press test, the upper body anaerobic Wingate cycle test was used to determine upper body power. The test was completed on a Monark Ergomedic (Model 891e, Sweden). Prior to the test, the subjects completed a 2-minute warm up against the $1 \mathrm{~kg}$ cradle weight at a speed of $>60 \mathrm{rpm}$. Following the warm-up, subjects completed a 6 second sprint in order to familiarize themselves further with the movement and the resistance on the cradle. Following this process and a 1 minute rest period, subjects pedaled with their upper body to maximum effort for a period of 30 seconds against a resistance of 50 $\mathrm{g} / \mathrm{kg}$ of total body mass (5\% of body mass) (19). Throughout the trials, verbal encouragement was provided to all subjects. During the test, subjects kneeled in a position with the buttocks remaining in contact with the heels at all times in order to reduce the use of the lower body. Throughout the Wingate test, peak power $(\mathrm{W})$, mean power $(\mathrm{W})$, relative peak power $(\mathrm{W} / \mathrm{kg})$ and relative mean power $(\mathrm{W} / \mathrm{kg})$ were collected and logged using Microsoft Excel.

\section{Data Analysis}


190

191

192

193

194

195

196

197

198

199

200

201

202

203

204

205

206

207

208

209

210

211

212

In order to analyze the golf performance variables, 5 of the 8 golf shots with the greatest CHV were selected (22). Following this, an average for CHV and ball velocity from the 5 golf shots was calculated. From the 2 ballistic bench press trials, the maximum measures for peak power $(\mathrm{W})$, mean power $(\mathrm{W})$, relative peak power $(\mathrm{W} / \mathrm{kg})$ and relative mean power $(\mathrm{W} / \mathrm{kg})$ variables were identified and used for the statistical analysis process. Peak power $(\mathrm{W})$, mean power $(\mathrm{W})$, relative peak power $(\mathrm{W} / \mathrm{kg})$ and relative mean power $(\mathrm{W} / \mathrm{kg})$ variables were analyzed from the Wingate test that was performed.

\section{Statistical Analysis}

All statistical analysis was performed using Jamovi (Version: 1.0.1). All data was measured for normality using the Shapiro-Wilk test. Normality was assumed for all data; therefore, Pearson product-moment correlations were carried out to determine relationships between upper body power variables and golf performance variables. Correlation coefficients of $0-0.3$ were categorized as weak, 0.3 to 0.5 moderate, 0.5 to 0.9 strong and 0.9 to 1 very strong (20), and $p \leq 0.05$ was considered significant. In addition, coefficient of determinations $\left(\mathrm{r}^{2}\right)$ were calculated to examine the amount of explained variance between upper body power variables and golf performance variables.

\section{RESULTS}

Descriptive statistics for CHV and ball velocity are presented within Table 1 . In addition, descriptive statistics for all ballistic bench press variables are presented within Table 2, and all Wingate variables are presented within Table 3. 
214 Table 1: Descriptive statistics for each golf performance variable when using the 7-iron and

215 Driver. Club head velocity (CHV).

\begin{tabular}{|c|c|c|c|c|c|c|}
\hline \multirow{3}{*}{$\begin{array}{c}\text { Golf } \\
\text { Performance } \\
\text { Variables }\end{array}$} & \multicolumn{3}{|c|}{ 7-iron } & \multicolumn{3}{|c|}{ Driver } \\
\hline & \multirow{2}{*}{ Mean \pm SD } & \multicolumn{2}{|c|}{$95 \% \mathrm{CI}$} & \multirow{2}{*}{ Mean \pm SD } & \multicolumn{2}{|c|}{$95 \% \mathrm{CI}$} \\
\hline & & Lower & Upper & & Lower & Upper \\
\hline CHV $(\mathbf{k m} / \mathbf{h})$ & $143.39 \pm 10.03$ & 137.69 & 148.32 & $165.36 \pm 11.46$ & 158.49 & 171.79 \\
\hline $\begin{array}{c}\text { Ball Velocity } \\
(\mathbf{k m} / \mathbf{h})\end{array}$ & $187.11 \pm 11.96$ & 180.66 & 194.73 & $242.10 \pm 16.70$ & 232.25 & 251.59 \\
\hline
\end{tabular}

217 Table 2: Descriptive statistics for each ballistic bench press variable.

\begin{tabular}{crr}
\hline Ballistic Bench Press Variables & \multicolumn{2}{c}{218} \\
Peak Power $(\mathbf{W})$ & $631.50 \pm 153.27220$ \\
Mean Power $(\mathbf{W})$ & $323.58 \pm 85.98$ & 221 \\
\hline Relative Peak Power $(\mathbf{W} / \mathbf{k g})$ & $8.14 \pm 2.33$ & 222 \\
Relative Mean Power $(\mathbf{W} / \mathbf{k g})$ & $4.17 \pm 1.22$ & 224 \\
\hline
\end{tabular}

Table 3: Descriptive statistics for each Wingate test variable.

\begin{tabular}{cc} 
Wingate Test & Mean \pm SD \\
\hline Peak Power $(W)$ & $396.49 \pm 89.23$ \\
Mean Power $(W)$ & $293.18 \pm 61.53$ \\
Relative Peak Power $(\mathbf{W} / \mathbf{k g})$ & $5.06 \pm 1.08$
\end{tabular}




\section{Relative Mean Power (W/kg) $\quad 3.74 \pm 0.70^{227}$}

230 Table 4 and Table 5 provide the Pearson's correlation coefficients, coefficient of 231 determinations and p-values for relationships between golf performance variables and upper 232 body power measures. Golf shots performed with the driver are presented within Table 4, and 233 golf shots performed with the 7-iron are presented in Table 5. Whilst using the driver, strong correlation coefficients were reported when measuring relationships between golf performance variables and ballistic bench press variables $(r>0.5)$. Significant relationships were observed for all golf performance variables and ballistic bench press variables $(\mathrm{p}<0.05)$. Coefficient of determinations for all significantly related variables were greater than $30 \%$ (Table 4). Specifically, absolute mean power during the ballistic bench press displayed the greatest predictor of CHV $\left(r^{2}=49 \%\right)$ and ball velocity $\left(r^{2}=50 \%\right)($ Table 4$)$.

Similarly, strong correlation coefficients were reported when measuring relationships between golf performance variables and Wingate test variables $(r>0.5)$ when using the driver. Significant relationships were observed for all golf performance variables when using the driver and Wingate test variables $(\mathrm{p}<0.05)$ with the exception of $\mathrm{CHV}$ and peak power, and ball velocity and peak and mean power during the Wingate test $(\mathrm{p}>0.05)$. Relative mean power was the greatest predictor of CHV $\left(r^{2}=60 \%\right)$ and ball velocity $\left(r^{2}=56 \%\right)$ (Table 4$)$. 


\begin{tabular}{|c|c|c|c|c|c|c|c|c|c|}
\hline \multirow{2}{*}{$\begin{array}{c}\text { Golf } \\
\text { Performance } \\
\text { Variables }\end{array}$} & \multirow{2}{*}{$\begin{array}{c}\text { Correlation } \\
\text { Analysis }\end{array}$} & \multicolumn{4}{|c|}{ Ballistic Bench Press } & \multicolumn{4}{|c|}{ Wingate Test } \\
\hline & & $\begin{array}{c}\text { Peak } \\
\text { Power (W) }\end{array}$ & $\begin{array}{c}\text { Mean } \\
\text { Power (W) }\end{array}$ & $\begin{array}{c}\text { RPP } \\
(\mathrm{W} / \mathrm{kg})\end{array}$ & $\begin{array}{c}\text { RMP } \\
(\mathrm{W} / \mathrm{kg})\end{array}$ & $\begin{array}{c}\text { Peak } \\
\text { Power (W) }\end{array}$ & $\begin{array}{c}\text { Mean } \\
\text { Power (W) }\end{array}$ & $\begin{array}{c}\text { RPP } \\
(\mathrm{W} / \mathrm{kg})\end{array}$ & $\begin{array}{c}\text { RMP } \\
(\mathrm{W} / \mathrm{kg})\end{array}$ \\
\hline \multirow{3}{*}{ CHV(km/h) } & Pearson's $r$ & 0.643 & 0.698 & 0.564 & 0.645 & 0.525 & 0.574 & 0.692 & 0.775 \\
\hline & $r^{2}$ & 0.413 & 0.487 & 0.318 & 0.416 & 0.276 & 0.329 & 0.479 & 0.601 \\
\hline & $p$ - value & 0.018 & 0.008 & 0.045 & 0.017 & 0.065 & 0.040 & 0.009 & 0.002 \\
\hline \multirow{3}{*}{$\begin{array}{l}\text { Ball Velocity } \\
\text { (km/h) }\end{array}$} & Pearson's $r$ & 0.663 & 0.704 & 0.587 & 0.657 & 0.500 & 0.539 & 0.672 & 0.745 \\
\hline & $r^{2}$ & 0.440 & 0.496 & 0.345 & 0.432 & 0.250 & 0.291 & 0.452 & 0.555 \\
\hline & $p$ - value & 0.013 & 0.007 & 0.035 & 0.015 & 0.082 & 0.057 & 0.012 & 0.004 \\
\hline
\end{tabular}

Table 4: Pearson's correlation coefficients $(r)$, correlation of determinations $\left(r^{2}\right)$ and p-values for golf driver performance variables when measured against the ballistic bench press and Wingate test. Club head velocity (CHV).

\footnotetext{
Bold indicates a significant relationship between variables. RPP $=$ Relative Peak Power, RMP $=$ Relative Mean Power.
} 
256 When golf shots were performed with the 7-iron, moderate to strong relationships between golf

257 performance variables and ballistic bench press variables were reported (Table 5). Significant

258 relationships were observed between $\mathrm{CHV}$ and all ballistic bench press variables $(\mathrm{p}<0.05)$,

259 with the exception of $\mathrm{CHV}$ and relative mean power $(\mathrm{p}>0.05)$. In relation to ball velocity,

260 when using the 7-iron a significant relationship was observed with mean power $(\mathrm{p}<0.05)$,

261 whereas all other relationships were not significant $(\mathrm{p}>0.05)$. Mean power was the greatest

262 predictor of $\mathrm{CHV}$ and ball velocity, explaining $39 \%$ and $32 \%$ of the variance respectively

263 (Table 5).

264

265 Strong correlation coefficients were reported when measuring relationships between golf

266 performance variables, when using the 7-iron, and upper body Wingate variables $(r>0.5)$.

267 Significant relationships were observed for all golf performance variables and Wingate test

268 variables $(\mathrm{p}<0.05)$. Relative mean power was the greatest predictor of $\mathrm{CHV}$ and ball velocity, explaining $64 \%$ and $53 \%$ of the variance, respectively (Table 5).

270

271

272

273

274

275 


\begin{tabular}{|c|c|c|c|c|c|c|c|c|c|}
\hline \multirow{2}{*}{$\begin{array}{c}\text { Golf } \\
\text { Performance } \\
\text { Variables }\end{array}$} & \multirow{2}{*}{$\begin{array}{c}\text { Correlation } \\
\text { Analysis }\end{array}$} & \multicolumn{4}{|c|}{ Ballistic Bench Press } & \multicolumn{4}{|c|}{ Wingate Test } \\
\hline & & $\begin{array}{c}\text { Peak } \\
\text { Power }(\mathrm{W})\end{array}$ & $\begin{array}{c}\text { Mean } \\
\text { Power }(\mathrm{W})\end{array}$ & $\begin{array}{c}\text { RPP } \\
(\mathrm{W} / \mathrm{kg})\end{array}$ & $\begin{array}{c}\text { RMP } \\
(\mathrm{W} / \mathrm{kg})\end{array}$ & $\begin{array}{c}\text { Peak } \\
\text { Power }(\mathrm{W})\end{array}$ & $\begin{array}{c}\text { Mean } \\
\text { Power }(\mathrm{W})\end{array}$ & $\begin{array}{c}\text { RPP } \\
(\mathrm{W} / \mathrm{kg})\end{array}$ & $\begin{array}{c}\text { RMP } \\
(\mathrm{W} / \mathrm{kg})\end{array}$ \\
\hline \multirow{3}{*}{ CHV (km/h) } & Pearson's $r$ & 0.567 & 0.621 & 0.498 & 0.571 & 0.572 & 0.640 & 0.701 & 0.801 \\
\hline & $r^{2}$ & 0.321 & 0.386 & 0.248 & 0.326 & 0.327 & 0.410 & 0.491 & 0.642 \\
\hline & $p$ - value & 0.043 & 0.024 & 0.083 & 0.042 & 0.041 & 0.018 & 0.008 & $<.001$ \\
\hline \multirow{3}{*}{$\begin{array}{l}\text { Ball Velocity } \\
(\mathbf{k m} / \mathbf{h})\end{array}$} & Pearson's $r$ & 0.468 & 0.563 & 0.377 & 0.475 & 0.573 & 0.637 & 0.629 & 0.726 \\
\hline & $r^{2}$ & 0.219 & 0.317 & 0.142 & 0.226 & 0.328 & 0.406 & 0.396 & 0.527 \\
\hline & $p$ - value & 0.107 & 0.045 & 0.204 & 0.101 & 0.041 & 0.019 & 0.021 & 0.005 \\
\hline
\end{tabular}

Bold indicates a significant relationship between variables. RPP $=$ Relative Peak Power, RMP $=$ Relative Mean Power.
Table 5: Pearson's correlation coefficients $(r)$, correlation of determinations $\left(r^{2}\right)$ and p-values for golf 7-iron performance variables when measured against the ballistic bench press and Wingate test. Club head velocity (CHV). 


\section{DISCUSSION}

285

286

287

288

289

290

291

292

293

294

295

296

297

298

299

300

301

302

303

304

305

306

307

The findings of the current study demonstrate that many of the power outputs from the ballistic bench press and Wingate test are significantly correlated with $\mathrm{CHV}$ and ball velocity when using the driver and 7-iron. Specifically, when performing golf shots with the driver, CHV and ball velocity were significantly related to all output measures from the ballistic bench press, however, a reduction in the number of significant relationships was displayed for the Wingate test. Although this was the case, these non-significant relationships between the driver and Wingate test were still within the strong category. Positive relationships were also displayed when comparing golf performance variables, whilst using the 7-iron, with the ballistic bench press and Wingate tests; however, a greater number of significant relationships were found in relation to the Wingate test. Additionally, the relationships that were not significant when comparing the 7-iron to ballistic bench press and Wingate tests were still within the moderate category. These findings enabled the original study hypotheses, positive relationships between golf performance and upper body power, to be accepted. As a result of the findings, power development of the upper body may positively impact CHV and ball velocity and, in turn, improve long game performance.

The significant relationships of the ballistic bench press outputs with $\mathrm{CHV}$ and ball velocity, whilst using the driver and 7-iron, highlights the importance of upper body power during long game performance. The current study displayed that absolute mean power during the ballistic bench press displayed the greatest predictor of $\mathrm{CHV}$ (49\% of the variance explained) and ball velocity (50\% of the variance explained); however, these predictors reduced to $39 \%$ and $32 \%$ when using the 7-iron. The discrepancies may be due to golfers the driver being used to maximize distance, hitting the ball as far as possible (23), whereas the 7-iron is mainly used 
for shots of approximately $150 \mathrm{~m}$, where high accuracy and precision is essential (8). Similar to the current study, previous studies have highlighted the importance of the role of the upper body muscles during the golf swing $(14,24,29)$. Several upper body muscles, including the pectoralis major, are highly active throughout the golf swing, particularly during the forward and acceleration phases $(14,24)$. During the ballistic bench press exercise, which was utilized within the current study, the pectoralis major plays a key role and is highly active throughout the movement, especially throughout the concentric phase (> 75\% IRP - isometric reference position) (16). The importance of the pectoral musculature within the golf swing is further supported by Gordon et al. (10) where these researchers established that the strength of the chest during a pec-deck motion significantly correlated with $\mathrm{CHV}$ when using the driver. Taking into consideration the importance of the concentric actions of the pectoralis major during the bench press exercise and during the forward and acceleration phases of the golf swing, these findings suggest that improving power and strength within the pectoralis major musculature can have a positive impact on golf driving performance.

In relation to skill level, Keogh and colleagues reported a moderate correlation for bench press strength when comparing high and low handicap golfers (15). Specifically, bench press strength of low handicap golfers was $17.4 \%$ higher than high handicap golfers. Although the relationship between handicap and upper body power capabilities were not assessed in the current study, CHV was significantly related to handicap within the study completed by Keogh and colleagues (15). Therefore, it can be assumed that golfers with a greater $\mathrm{CHV}$ have greater chest press strength. Read et al. (25) also reported that a medicine ball chest throw, which targets the pectoral musculature, was significantly related to $\mathrm{CHV}$. These previous findings and the current findings in relation to the positive relationships between pectoral muscular exercises and golf performance variables suggest that improving the power and strength of the 
pectoral muscles can have a positive impact on long game performance, particularly when using the driver. Although this is a reasonable suggestion due to the significant relationships between upper body capabilities and golf performance, longitudinal research is required in order to highlight the benefits of developing power output from pectoral muscles throughout a training program with the aim of improving golf performance variables, including $\mathrm{CHV}$ and ball velocity.

In addition to the significant relationships between the ballistic bench press and golf performance, the current study also identifies positive correlations with upper body power output during the Wingate test and golf performance measures when using the driver and 7iron. In addition, the current study demonstrated that relative mean power during the Wingate test displayed the greatest predictor of $\mathrm{CHV}$ (60\% of the variance explained) and ball velocity (56\% of the variance explained) when using the driver. Similarly, relative mean power during the Wingate test displayed the greatest predictor of $\mathrm{CHV}(64 \%$ of the variance explained) and ball velocity (53\% of the variance explained) when using the 7-iron. In relation to the driver, there was a reduction in the number of significant relationships between the Wingate test and golf performance measures when compared to the ballistic bench press. Although this was the case, all non-significant relationships were within the moderate and strong category. These reductions in the number of significant relationships may be due to the fact that different muscles are targeted by the two exercises. The Wingate test predominately targets the bicep brachii, tricep brachii and deltoid musculature (27), whereas the ballistic bench press predominately targets the pectoralis major and deltoid musculature (24). Although both movements target the deltoid area, development of the pectorals may be of greater importance when aiming to improve driving performance. During the downswing and acceleration phases of the golf swing, the pectoral muscles display significantly higher muscle activation when 
compared to the deltoid muscles (24). These greater pectoral muscle activations during the golf swing may explain why the current results display a greater number of significant relationships when comparing golf driving performance with the ballistic bench press than with the Wingate test. Another factor, which may explain different relationships observed between the ballistic bench press and Wingate tests, could be that the former test peak power requires a sustained effort across five seconds whereas the ballistic bench press only required one maximal movement. Considering the golf swing is one dynamic movement (9), this is better replicated by the ballistic bench press than the Wingate test, especially when the golf swing is performed at higher velocities with the driver when compared to the 7-iron.

Although there was a reduction in the number of significant relationships between the Wingate test and golf performance variable when using the driver, all Wingate test variables were significantly correlated with the 7-iron. Discrepancies between the driver and 7-iron may be due to golfers displaying a larger variation in technique when performing golf shots with the driver when compared to golf shots with iron clubs (13). Furthermore, a tighter cluster of CHV and ball velocities when using the 7-iron in comparison to using the driver may have resulted in stronger relationships. With this being said, it must be highlighted that the Wingate test variables that were not significantly correlated when using the driver were within the moderate relationship category.

It is important to recognize the limitations associated with the current study. All golf performance sessions took place at a local driving range, which did not allow for a laboratorycontrolled setting. However, with the sessions taking place at a driving range, golfers were provided with a greater practical experience. In addition, only $\mathrm{CHV}$ and ball velocity were 
measured in the current study, therefore, centeredness of the strike and accuracy of the golf shots were not assessed. It is also important to recognize that the current findings are based upon relationships between upper body capabilities and golf performance. As a result of the positive relationships displayed in the current study, future research should aim to investigate causation when considering upper body power capabilities and golf performance. Furthermore, only two exercises were used to assess the relationship between upper body power and golf performance. Future research should aim to investigate the relationship between the power output of additional upper body movements and golf performance.

\section{PRACTICAL APPLICATIONS}

The result of the current study suggests that there is a moderate to strong relationship between upper body power output during the ballistic bench press and Wingate test and golf performance variables. As a results, both the ballistic bench press test and the Wingate test can be used as a primary assessment to measure the effectiveness of upper body training interventions with the aim of improving golf performance. In relation to driving performance, the number of significant relationships were greater when compared to the ballistic bench press test; therefore this test may be more appropriate for strength and conditioning coaches to use when assessing their golfers' upper body power capabilities relative to their driving performance. This is suggested due to the golf swing being one dynamic movement and, therefore, being better replicated during the ballistic bench press than the Wingate test, especially when the golf swing if performed at higher velocities with the driver when compared to the 7-iron. Additionally, with identified relationships between upper body power during the ballistic bench press and golf drive performance, both strength and conditioning and golf coaches should be made aware and consider adopting upper body exercises shown to improve 
406

407

408

409

410

411

412

413

414

415

416

417

418

419

420

421

422

423

424

425

426

427

upper body power. However, more evidence regarding the efficacy of upper body training is needed in order to confirm this suggestion. These findings can also be utilized to inform future research designs in relation to strength and conditioning research.

\section{ACKNOWLEDGEMENTS}

The results of the current study do not constitute endorsement by the authors or the National Strength and Conditioning Association. No external funding was received for the current study.

\section{REFERENCES}

1. Bechler, J, Jobe, F, Pink, M, and Perry, J. Electromyographic analysis of the hip and knee during the golf swing . Clin J Sport Med 5: 151-217, 1995.

2. Brown, SJ, Nevill, AM, Monk, SA, Otto, SR, Selbie, WS, and Wallace, ES.

Determination of the swing technique characteristics and performance outcome relationship in golf driving for low handicap female golfers. J Sports Sci 29: 1483-91, 2011.Available from: http://www.ncbi.nlm.nih.gov/pubmed/21988676

3. Brzycki, M. Strength testing: predicting a one-rep max from reps to fatigue. JOPERD, 1993.

4. Chu, Y, Sell, TC, and Lephart, SM. The relationship between biomechanical variables and driving performance during the golf swing. J Sports Sci 28: 1251-1259, 2010.

5. Clark, R, Bryant, A, and Humphries, B. A comparison of force curve and profiles between the bench press and ballistic bench press and ballistic bench throws. $J$ strength Cond Res 22: 1755-1759, 2008. 
6. Cole, $\mathrm{MH}$ and Grimshaw, PN. The X-Factor and its relationship to golfing performance. J Quant Anal Sport 5: 1-20, 2009.

7. Doan, BK, Newton, RU, Kwon, Y-H, and Kraemer, WJ. Effects of physical conditioning on intercollegiate golfer performance. J Strength Cond Res 20: 62-72, 2006.Available from: http://www.ncbi.nlm.nih.gov/pubmed/16503694

8. Egret, CI, Vincent, O, Weber, J, Dujardin, FH, and Chollet, D. Analysis of 3D kinematics concerning three different clubs in golf swing. Int J Sports Med 24: 465470, 2003.

9. Fletcher, IM and Hartwell, M. Effect of an 8-week combined weights and plyometrics training program on golf drive performance. J strength Cond Res 18: 59-62, 2004.

10. Gordon, B, Moir, G, Davis, S, Witmer, C, and Cummings, D. An investigation into the relationship of flexibility, power, and strength to club head speed in male golfers. $J$ strength Cond Res 23: 1606-1610, 2009.

11. Hetu, F, Christie, C, and Faigenbaum, A. Effects of conditioning on physical fitness and club head speed in mature golfers. Percept Mot Skills 86: 811-815, 1998.

12. Hume, PA, Keogh, J, and Reid, D. The role of biomechanics in maximising distance and accuracy of golf shots. Sport Med 35: 429-449, 2005.

13. Joyce, C, Burnett, A, Cochrane, J, and Ball, K. Three-dimensional trunk kinematics in golf : between-club differences and relationships to clubhead speed. Sport Biomech 12: 108-120, 2013.

14. Kao, J, Pink, M, Jobe, FW, and Perry, J. Electromyographic analysis of the scapular muscles during a golf swing. Am J Sports Med 23: 19-23, 1995.

15. Keogh, J, Marnewick, MC, Maulder, PS, Nortje, JP, Hume, PA, and Bradshaw, EJ. 
Are anthropometric, flexibility, muscular strength, and endurance variables related to clubhead velocity in low- and high-handicap golfers? J Strength Cond Res 23: 18411850, 2009.Available from: http://content.wkhealth.com/linkback/openurl?sid=WKPTLP:landingpage\&an=001242 78-200909000-00030

16. Król, H and Gołás, A. Effect of barbell weight on the structure of the flat bench press. J Strength Cond Res 31: 1321-1337, 2017.

17. Lephart, S, Smoliga, J, Myers, J, Sell, T, and Tsai, Y. An eight-week golf-stretching exercise program improves physical characteristics, swing mechanics, and golf performance in recreational golfers. J Strength Cond Res 21: 860-869, 2007.

18. Loock, H, Grace, J, and Semple, S. Association of selected physical fitness parameters with club head speed and carry distance in recreational golf players. Int J Sports Sci Coach 8: 769-777, 2013.

19. Lovell, D, Mason, D, Delphinus, E, Eagles, A, Shewring, S, and McLellan, C. Does upper body strength and power influence upper body wingate performance in men and women? Int J Sports Med 32: 771-775, 2011.

20. Marshall, E. The Statistics Tutor's Quick Guide to Commonly Used Statistical Tests. Statstutor Community Proj University: 1-53

21. Marta, S, Silva, L, Vaz, JR, Castro, MA, and Pezarat-correia, P. Electromyographic analysis of lower limb muscles during the golf swing performed with three different clubs. J Sports Sci 38: 713-720, 2015.

22. Myers, J, Lephart, S, Tsai, Y-S, Sell, T, Smoliga, J, and Jolly, J. The role of upper torso and pelvis rotation in driving performance during the golf swing. J Sports Sci 26: 
181-188, 2008.Available from: http://www.tandfonline.com/doi/abs/10.1080/02640410701373543

23. Nagao, N and Sawada, Y. A kinematic analysis in golf swing concerning driver shot and No. 9 iron shot. J Sports Med Phys Fitness 13: 4-16, 1973.

24. Pink, M, Jobe, FW, and Perry, J. Electromyographic analysis of the shoulder during the golf swing. Am J Sports Med 18: 137-140, 1990.

25. Read, P, Lloyd, R, Croix, M, and Oliver, J. Relationships between field-based measures of strength and power and golf club head speed. J strength Cond Res 27: 2708-2713, 2013.

26. Silva, L, Marta, S, Vaz, J, Fernandes, O, Castro, MA, and Pezarat-Correia, P. Trunk muscle activation during golf swing: Baseline and threshold. J Electromyogr Kinesiol 23: 1174-1182, 2013.

27. Smith, PM, Chapman, ML, Hazlehurst, KE, and Goss-sampson, MA. The influence of crank configuration on muscle activity and torque production during arm crank ergometry. J Electromyogr Kinesiol 18: 598-605, 2008.

28. Sorbie, GG, Gu, Y, Baker, JS, and Ugbolue, UC. Analysis of the X-Factor and XFactor stretch during the completion of a golf practice session in low-handicap golfers. Int J Sports Sci Coach 1001-1007, 2018.

29. Sorbie, GG, Hunter, HH, Grace, FM, Gu, Y, Baker, JS, and Ugbolue, UC. An electromyographic study of the effect of hand grip sizes on forearm muscle activity and golf performance. Res Sport Med 24, 2016.

30. Sorbie, GG, Low, C, and Richardson, AK. Effect of a 6-week yoga intervention on swing mechanics during the golf swing: a feasibility study during the golf swing: a 
497

498

499

500

501

502

503

504

505

506

507

508

509

510

511

512

513

514

515

516

517

31. Tilley, NR and Macfarlane, A. Effects of different warm-up programs on golf performance in elite male golfers. Int J fo Sport Phys Ther 7: 388-395, 2012.

32. Watkins, R, Uppal, G, Perry, J, Pink, M, and Dinsay, J. Dynamic electromyographic analysis of trunk musculature in professional golfers. Am J Sports Med 24: 535-538, 1996.

33. Wells, JET, Charalambous, LH, Mitchell, ACS, Brearley, SL, Hawkes, RA, Murray, AD, et al. Relationships between Challenge Tour golfers ' clubhead velocity and force producing capabilities during a countermovement jump and isometric mid-thigh pull. $J$ Sports Sci 37: 1381-1386, 2019.Available from:

https://doi.org/10.1080/02640414.2018.1559972

.

. 
Appendix 1- Standardized Dynamic Warm-up performed prior to the golf test.

\begin{tabular}{|c|c|c|c|}
\hline Exercise & Description & Sets & Reps \\
\hline Trunk Rotations & $\begin{array}{l}\text { Start } 6 \text { to } 8 \text { inches from the wall; subject were asked to begin turning their right side of their body } \\
\text { towards the wall. Subjects were then instructed to reach their right and left hands towards the wall. } \\
\text { Repeat on both sides. }\end{array}$ & 1 & 10 \\
\hline Trunk Rotations & $\begin{array}{l}\text { position. Subjects were instructed to keep their right knee above their right foot and their left knee } \\
\text { just off the ground. When in the lunge position rotate the trunk to the right side with the arms at head } \\
\text { height. Return to the start position and repeat on the left side. }\end{array}$ & & \\
\hline
\end{tabular}


Shoulder Begin with the shoulder at 90 degrees abduction. Subject were then instructed to bring their palms

1

10

Rotations towards the posterior side of the body followed by the anterior side of the body, keeping the elbows

in full extension and moving shoulder in circumduction.

Practice Swing

$\operatorname{Pr}$

swing. Practice swings were repeated with the driver.

Full swing shots Full golf shots were performed with the driver. Subjects were asked to perform their standard golf 